Hoppe-Seyler, F. (1894). Hoppe-Seyl. Z. I9, 574.

Jaquet, A. (1903). Verh. naturf. Ges. Basel, 15, 252.

Kofrányi, E. \& Michaelis, H. P. (1940). Arbeitsphysiologie, I1, 148.

Krogh, A. (1906). Skand. Arch. Physiol. 18, 364.

Krogh, A. \& Lindhard, J. (I920). Biochem. F. 14, 290.

Lavoisier, A. L. (1775-85). CEuvres de Lavoisier. Vol. 2, Paris: Imprimerie Imperiale, 1865.

Lilly, J. C. (1946). Fed. Proc. 5, 64.

Magnus-Levy, A. (1894). Pfiüg. Arch. ges. Physiol. 55, I.

Pauling, L., Wood, R. E. \& Sturdivant, J. H. (1946). Science, 103, 338.

Pettenkofer, M. (1862). Ann. Chem. Pharm. Suppl. Bd. 2, I.

Pettersson, O. \& Sondén, K. (1895). Skand. Arch. Physiol. 6, I6.

Regnault, V. \& Reiset, J. (I 849). Ann. Chim. (Phys.), 26 (3), 299.

Rein, H. (1933). Arch. exper. Path. Pharmak. 171, 363.

Rubner, M. (1894). Z. Biol. 30, 73.

Smith, E. (1859a). Philos. Trans. 149, 681.

Smith, E. (1859b). Philos. Trans. 149, 715.

Sondén, K. \& Tigerstedt, R. (1895). Skand. Arch. Physiol. 6, I.

Speck, C. (1 892). Physiologie des meschlichen Athmens nach eigenen Untersuchungen. Leipzig.

Tigerstedt, R. (1906). Skand. Arch. Physiol. r8, 298.

Tissot, F. (1904). F. Physiol. Path. gén. 6, 688.

Voit, C. (1875). Z. Biol. 11, 532.

von der Heide, Klein, \& Zuntz, N. (1913). Z. wiss. Landwirtschf. 44, 765.

Zuntz, N. Loewy, A., Müller, F. \& Caspari, W. (1906). Höhenklima und Bergwanderungen. Berlin: Bong \& Co.

\title{
Modern techniques for measuring energy expenditure
}

By H. S. Wolff, Division of Human Physiology, National Institute for Medical

Research, Medical Research Council, c/o Medical Research Council Laboratories, Holly Hill, Hampstead, London, N.W.3

All instruments measuring energy expenditure by indirect calorimetry must have the following functions. They must measure the volume of air expired over a given time, and produce a sample representative of the whole experimental period.

The Douglas bag (Douglas, I9II) is a special instance of such an 'instrument' in which all the air is collected and is available for subsequent analysis and volume measurement. It is just those qualities which make the Douglas bag an absolute method for laboratory work that militate against its employment in the field.

It has become customary in recent years to attempt to follow the energy expenditure of people over long periods with a view to establishing either a calorie balancesheet of input against output, or to assess the 'hardness' of a given employment or task.

For such an investigation long-term measurements have to be carried out under conditions of minimal interference with normal activity.

The qualities which a suitable instrument must possess are the following:

(I) The weight and the resistance to respiratory air flow must be sufficiently low to impose only a negligible physiological load, both subjectively and objectively.

(2) The integrated sample produced at the finish must be as similar as possible in composition to the mixed contents of a very large Douglas bag, if such had been used. 
(3) The mechanical construction must be such that the result is independent of the position of the instrument, and sufficiently sturdy to withstand the knocks and accelerations which it will undoubtedly suffer if it is good enough not to remind the wearer continually of its presence.

The first solution to this problem was an adaptation of the bellows-type gas meter to measure the volume of the expired air. A diaphragm pump was geared to the mechanism in such a way that a small but constant fraction of the air passing through the meter was pumped into a rubber bladder. The meter is worn on the back and is connected by a corrugated rubber tube to a mask or mouthpiece fitted with inlet and outlet valves. Instruments of this type have culminated in the Kofrányi \& Michaelis (1940) calorimeter of the Max Planck Institute. It weighs about $6 \mathrm{lb}$, has two sampling rates, and under favourable conditions can be very accurate.

It suffers from the limitations that it is not really designed to deal with ventilation rates in excess of $301 . / \mathrm{min}$ and that it may be sensitive to position and acceleration. Furthermore, as all the mechanical work of emptying and filling the bellows and driving the sampling pump has to be supplied by the respiration of the subject, the back pressure is not as low as might be desired.

This instrument has been successfully employed in a number of surveys; the application in general, however, has been to measure the energy expenditure of a specific activity over a relatively short time, and to build up the expenditure over a much longer period by a 'time-and-motion' study, into which the experimentally determined values were substituted later.

More recently the need has arisen for a new calorimeter that could be worn over long periods, and that should be capable of working over the range $6-801 . / \mathrm{min}$. After an examination of the problem by the author it was concluded that conventional gas-meter technique had probably been taken as far as possible with the Kofrányi-Michaelis calorimeter and that an increase in range could only be obtained by an increase in size which was undesirable.

The instrument that was developed, known as the IMP (Integrating Motor Pneumotachograph), consists of a flow meter of novel construction attached to a lowresistance mask. The flow meter produces a voltage output which is always proportional to instantaneous flow. The voltage is integrated mechanically by a very low friction permanent magnet motor which has a linear voltage : speed characteristic. The number of revolutions which the motor executes is proportional to the time integral of the voltage and hence of the flow. A mechanical counter geared to the motor therefore gives a direct reading of volume.

A commutator driven by the same motor actuates an electromagnetic pump every few litres which snatches a small sample from the flow meter via a PVC (polyvynilchloride) tube and pumps it into a plastic bag. The snatch time is very short and occurs at a random point of the expiratory cycle. In any one experiment the total number of small samples is large, so that the integrated sample fulfils the conditions mentioned above. Neither the inspiratory nor the expiratory pressure drop ever exceeds $2.5 \mathrm{~cm}$ water even at the highest flow rates. The weight of the latest model including batteries for $50 \mathrm{~h}$ is about $4 \mathrm{lb}$. 
In about $1000 \mathrm{~h}$ of use on army recruits in infantry training, with a rather heavier model, there was no evidence that they were physically handicapped in any way.

A serious problem for which no entirely satisfactory solution exists as yet, is the long-term collection and storage of a rather small sample during the experiment. To keep the instrument dimensions down the sample-bag volume has been restricted to $500 \mathrm{ml}$. For such a small bag the surface : volume ratio is very adverse. Though there are plastics less permeable to $\mathrm{CO}_{2}$ and $\mathrm{O}_{2}$ than rubber, there is no plastic that has been tried, sufficiently impermeable to keep a sample intact in air for $2 \mathrm{~h}$. There appears to be a rough proportionality between the permeability of a plastic sheet and its stiffness. This means that good materials have to be used in a thinner gauge to make a sufficiently flexible bag and not much is gained. The present practice is to enclose the sample bag in an air-tight tin fitted with an outward-facing nonreturn valve. Connexions to the interior of the bag and of the tin are brought out through the lid and can be clipped off. The tin is filled with expired air which escapes through the valve as the bag fills. This reduction in concentration gradient across the bag walls helps to preserve the sample and allows one to obtain energyexpenditure figures that are in agreement with those obtained by other methods. For investigations lasting hours rather than minutes it is quite essential to use a mask rather than a mouthpiece. The mask is a development of the R.A.F. $H$ type mask and has on occasions been worn for 7 oh/week without apparent discomfort or damage to the underlying skin. The inlet resistance is low, i.e. at $2001 . / \mathrm{m}$ it does not exceed $\mathrm{r} \cdot 9 \mathrm{~cm}$ water. There are three inlet valves so arranged that the cool air blows over the nose and cheeks, a fact which appears to add greatly to the subject's comfort. An attachment is fitted which allows drinking and smoking, though the latter should not be permitted if it occupies an appreciable fraction of the experimental period. The IMP does not require an expiratory valve because the flow-meter does not permit reverse flow.

In many applications it is not only the total expenditure that is of interest but its distribution in time. To give some indication of this, arrangements have been made to measure ventilation rate continuously at a distance. It has been shown that for a given subject wearing an instrument of a given type there is a reasonable proportionality between ventilation rate and energy expenditure.

A small radio transmitter weighing only $8 \mathrm{oz}$., either without any external aerial at all, or with a 12 in. whip, is worn by the subject, and transmits continuously. Contacts in the integrating unit switch off the transmitter for a few msec every few litres. These breaks in transmission are counted by a receiver up to 500 yd. away and displayed in an easily readable form. If the design of the receiver is such that even a small signal from the transmitter will make it insensitive to other signals, and if furthermore it is made impossible to register more than one count during one transmission break, the sytem is virtually proof against normal or even quite severe outside interference.

Preliminary results of measurements carried out on army recruits have demonstrated only a short time lag between the onset of a more vigorous type of activity and an increased ventilation rate, and the rather peaky nature of many types of work. 
The bottleneck in the application of indirect calorimetry is still the need for laborious and skilful gas analysis. It is this bottleneck that is now under attack in this laboratory. If the attack is successful, the results will be, first a robust oxygen analyser for laboratory use, with a very short response time and small dead space, and later an adaptation of it sufficiently light to be carried by the subject. This in combination with a flow meter will produce an answer directly in terms of oxygen consumption.

\section{REFERENCES}

Douglas, C. G. (191 1). F. Physiol. 42, xvii.

Kofrányi, E. \& Michaelis, H. F. (I940). Arbeitsphysiologie, II, I48.

\section{Energy expenditure in relation to nutrition}

By O. G. Edholm, Division of Human Physiology, National Institute for Medical Research, Medical Research Council, c/o Medical Research Council Laboratories, Holly Hill, Hampstead, London, N.W.3

The two sides of the energy balance have had uneven treatment in the past. Calorie intake has been very thoroughly investigated, and the techniques of dietary surveys have been brought to a high standard of accuracy. Tables giving the calorie values of nearly all foods and drinks are available, so it is not surprising that there is such a volume of information available on calorie consumption.

There is also a very considerable literature on the energy expenditure on particular activities, but less information on total energy expenditure. The methods which can be employed have been described by Douglas (I956) and Wolff (1956). Up to the present, direct calorimetry is the only method by which continuous recording of energy expenditure for a long time can be obtained.

The limitations of direct calorimetry are the expense of the construction of a suitable chamber, the restrictions imposed on the activity of the subject, and the fact that such investigations must be made in the laboratory. Indirect calorimetry can be used in the field but continuous recording of activity is difficult, and in practice energy expenditure is measured by recording for brief intervals and applying the values obtained for the whole period of time occupied by that activity.

Computation is therefore the basis for calculating energy expenditure. The information necessary is:

(I) A list of the activities of the day and the time spent on each.

(2) The energy expenditure on each of these activities. The simplest type of calculation would be one which has been frequently used, i.e. division of the day into $8 \mathrm{~h}$ sleep, $8 \mathrm{~h}$ work, and $8 \mathrm{~h}$ recreation. The calorie expenditure during sleep can be taken as equal to the basal metabolic rate. The $8 \mathrm{~h}$ off work can be assumed to be approximately $3 \times$ B.M.R., leaving the energy expenditure during work as the main variable, and studies outside the laboratory have therefore been mainly concerned with this variable. 